\title{
The need of close monitor of the patients infected with the 2019 novel coronavirus (SARS-Cov-2) in one designated medical institutions in Chengdu: a single-center, retrospective, observational study
}

Gui Zhou

Chengdu Fifth People's Hospital

Yun-Hui Tan

Chengdu Fifth People's Hospital

Yi-Xiao Lu

Nagasaki Daigaku

Jiang-Cuo Luo

Chengdu Fifth People's Hospital

Jing Feng

Anhong Township Health Hospital

Juan Li

Pidu District People's Hospital

Yun-Mei Yang

Chengdu Fifth People's Hospital

Long Chen

Chengdu Fifth People's Hospital

Jianping Zhang ( $\sim$ zhangjianping1962@qq.com )

Kunming Medical University https://orcid.org/0000-0002-7593-8154

Research article

Keywords: COVID-19, Clinical feature, SARS-Cov-2019, Case study

Posted Date: March 18th, 2020

DOl: https://doi.org/10.21203/rs.3.rs-17876/v1

License: (1) This work is licensed under a Creative Commons Attribution 4.0 International License.

Read Full License 


\section{Abstract}

Objective: To study the clinical characteristics of COVID-19 patients in one designated medical institutions in Chengdu.

Methods: 20 patients admitted to one hospital in designated medical institutions in Chengdu with laboratory confirmed SARS-Cov-2 infection. Data were collected from 26 January 2020 to 1 March 2020. Clinical data were collected using Self-constructed questionnaire refer to World health organization nCoV CASE RECORDFORM Version 1.2 28JAN2020. If information was not clear, The team will review the original data from the designated computer.

Results: Of the 20 COVID-19 infected patients studied (median age 42.5 years), 4 patients became severe sick and one was critical deteriorated in the process of treatment, they were later transferred to the superior medical institutions for treatment. This patient died after admitted to the intensive care unit (ICU). The other two mild patients remained positive for pharyngeal swabs of SARS-Cov-2 more than 3 weeks, so they were quarantined in a medical facility without medication. All studied cases were infected by human to human transmission without taking protective measures. It requires further confirmation of transmission through contact within families. The most common symptoms at onset of illness were fever in $13(65 \%)$ patients, cough in $9(45 \%)$, headache in $3(15 \%)$, fatigue in $6(30 \%)$, diarrhoea in $3(15 \%)$, and Abdominal pain in $2(10 \%)$. Six patients (30\%) developed shortness of breath on admission. The median time from exposure to onset of illness was 6.5 days (interquartile range 3.25-9 days), and from the onset of symptoms to first hospital admission was 3.5(1.25-7) days.

Conclusion: Up to the end of February 2020, compared with patients initially infected with SARS-Cov-2 in Wuhan, the symptoms of patients in this study was relatively mild and the patients are easily cured and discharged from hospital. the patients with mild symptoms of COVID-19 is general type of patients infected with SARS-Cov-2 in China. However, The COVID-19 is a self-limiting disease with no effective drug to treat it, it is important to detect and identify severe cases from mild cases early.

\section{Introduction}

In the past few decades, there have been epidemics of respiratory infections caused by emerging viruses, they were originated in animals, severe respiratory syndrome coronavirus (SARS-CoV), Middle East respiratory syndrome coronavirus (MERS-CoV) and pandemic influenza A (H1N1) crossed the species barriers to infect humans caused thousands of infections and hundreds of deaths ${ }^{1}$. Currently, a mysterious outbreak of atypical pneumonia in late 2019 was traced to a seafood wholesale market in Wuhan of China. Within a few weeks, a novel coronavirus tentatively named as 2019 novel coronavirus (2019-nCoV) was announced by the World Health Organization ${ }^{2}$. Soon later, a novel coronavirus (SARSCoV-2) causes the outbreaks of Coronavirus Disease 2019 (COVID-19) was confirmed. Full-length genome sequences were obtained from five patients at the early stage of the outbreak. They are almost identical to each other and share $79.5 \%$ sequence identifies to SARS-CoV. Furthermore, it was found that 
2019-nCoV is $96 \%$ identical at the whole-genome level to a bat coronavirus ${ }^{3}$. There is a worldwide concern about the new coronavirus 2019-nCoV as a global public health threat ${ }^{4}$. On 30 January 2020 , the WHO declared COVID-19 as the sixth public health emergency of international concern. SARS-CoV-2 is closely related to two bat-derived severe acute respiratory syndrome-like coronaviruses, bat-SL-CoVZC45 and bat-SL-CoVZXC21. It is spread by human-to-human transmission via droplets or direct contact ${ }^{5}$, later, to explore the potential intermediate animal host of the SARS-CoV-2 virus, the researchers re-analyzed virome datasets from pangolins and representative SARS-related coronaviruses isolates from bats, with particular attention paid to the spike glycoprotein gene. The recent outbreak of COVID-19, did not come directly from pangolins ${ }^{6}$.

Until March 1, 2020, there are 79972 confirmed COVID-19 cases (including 7365 severe cases now) and 2873 deaths in China. There are 7651 confirmed COVID-19 cases and 118 deaths in other country. Some capital economists however, estimate that, without urgent global actions to curtail the Wuhan 2019-nCoV within the shortest possible time, China is expected to lose up to $\$ 62$ billion in the first quarter of the year, while the world is likely to lose over $\$ 280$ billion within the same period ${ }^{7}$. To control COVID-19, effective prevention and control measurements must include early detection, diagnosis, treatment, and quarantine in order to block human-to-human transmission as well as reducing secondary infections among close contacts and health care workers ${ }^{8}$. The local government restricted the importation of patients externally and the diffusion of patients internally, and determined designated medical institutions for the treatment of diseases in Chengdu, China. World widely, It is also actively advocates to establish the mechanism to prevent and control the epidemic of COVID-19 soon.

The working group describes the clinical characteristics and laboratory findings of patients in Sichuan province infected with SARS-Cov-2 to provide an insight into the prevention and treatment of COVID-19 across China and elsewhere. It will lead to severe infection to die if these patients cannot identify severe patients without management early.

\section{Methods}

\section{Data sources}

The working group conducted a retrospective study focusing on the clinical characteristics of confirmed cases of COVID-19 in designated medical institutions in Chengdu from 26 January 2020 to 1 March 2020. Since the outbreak of COVID-19 in Wuhan, China, strict precautionary measures has been implemented in Sichuan province. Including the creation of fever clinics that exclusively receive patients with suspected SARS-Cov-2 infection, defined as presenting with a fever or any respiratory symptoms, including dry cough, and especially in those with a history of travel to Wuhan or exposure to infected people within two weeks before the onset of illness since January 2020. Travel to the area where the disease is endemic or come into contact with a confirmed patient in the area, it is clustered incidence events in families. Case definitions of confirmed human infection with SARS-Cov-2 are in accordance 
with the interim guidance from the World Health Organization. An Ingenuity CT scanner (Philips (China) co. LTD) was used and set at $210 \mathrm{~mA}$ and $120 \mathrm{kV}$, with the minimum slice thickness of $1 \mathrm{~mm}$.

Only the patients with a laboratory confirmed infection were enrolled in this study. The working group collected data on 20 patients admitted to hospital with laboratory confirmed of SARS- Cov-2 infection in designated medical institutions in Chengdu, Sichuan province. Information was collected on dates of illness onset, visits to clinical facilities, and hospital admissions. Epidemiological data were collected through brief interviews with each patient. Several doctors interviewed each patient to collect exposure histories during the two weeks before illness onset or after the outbreak of COVID-19 in Wuhan, including the dates and times of close contact (gathering, living, or working together) with individuals from Wuhan with confirmed or suspected SARS-Cov-2 infection. It also investigated the social network of patient life, including family social network, friend social network, colleague social network and so on.

The working group extracted the medical records of patients by using World health organization nCov CASE RECORD FORM and Self-made scale. A team of doctors who had been treating patients with COVID-19 collected and reviewed the data. The design of the study process was based on Chinese national diagnosis and treatment plan without any intervention measures, concerned about privacy of patients, informed patients of specific rules, and conducted with the informed consent of patients. All information on the content of the study shall be kept by a special person for inspection necessary.

It was urgent need to collect data on this emerging pathogen that the requirement for informed consent was waived. Using a standardized case report form to collect clinical data according to design requirements, the working group would contact the doctor responsible for the treatment of the patient for clarification if the information were not clear.

\section{Laboratory confirmation and treatment}

Throat swab specimens were collected from all patients before entering the isolation ward, and were tested by real time polymerase chain reaction (rt-PCR) for SARS-Cov-2 RNA in Local centers for disease control and prevention (CDC). Laboratory confirmation of the virus was performed using real time reverse transcription polymerase chain reaction (rt-PCR). Virus detection was repeated twice with at least 24 hours interval. The patient enters the observation ward to stay monitoring if the patient is undiagnosed or returns home for self-monitoring. The patients will be admitted to an isolation ward for treatment if they are diagnosed with COVID-19 at a designated facility ,the patients can also be transferred to designated medical institutions who were diagnosed CIVOD-19 in other medical institutions. All 20 patients in this study came from isolation wards in designated medical institutions.

Laboratory tests were conducted at admission, including a complete blood count, serum biochemistry, and identification of other respiratory pathogens such as influenza A virus, influenza B virus, and nine infectious markers. Early antiviral treatment could alleviate disease severity and prevent illness progression, found lopinavir/ritonavir combined with arbidol showed antiviral effects in COVID-19. Most patients received antiviral treatment with interferon alpha inhalation (50 $\mu \mathrm{g}$ twice daily), lopinavir and 
ritonavir (400 mg twice daily and $100 \mathrm{mg}$ twice daily, respectively), and arbidol (200 mg twice daily) according to treatment plan. Oral Benadol (400mg once daily) were administered if the patient lasted fever for few days. The patient was treated with montmorillonite powder for diarrhea. Also integrated Chinese medicine in treatment to promote disease rehabilitation through classification methods of traditional Chinese medicine. In a ward, the treatment of general mild disease patients is to use symptomatic treatment, patients suspected of being infected with SARS-Cov-2 were discharged from hospital once the results of two rt-PCR reaction tests taken with 24 hours interval were negative for SARSCov-2 antigens.

\section{Statistical analysis}

As a previous study has shown that COVID-19 is a self-limited disease and patients generally recovered gradually after treatment, the working group collected clinical indicators for three times. The first time was 1 day after admission, the second time was 3 days after admission, and the third time was 5 days after admission. Of course, a range of clinical indicators are also the first to be included when the condition of patient suddenly changes. Summarized continuous variables as either means and standard deviations or medians with interquartile ranges. For categorical variables, the team calculated the percentages of patients in each category. All analyses were done with SPSS software, version 17.0.

\section{Patient and public involvement}

This was a retrospective case series study and no patients were involved in the study design, also, there were no controls or interventions for patients, setting the research questions by research questionnaire, or the outcome measures directly. No patients were asked to advise on interpretation or writing up of results.

\section{Results}

\section{Epidemiological characteristics}

By 1 March 2020, clinical data were collected on 20 patients with laboratory confirmed SARS-Cov-2 infection in Sichuan province. Nine (45\%) patients aged between 20 to 39 years, Seven (35\%) cases aged between 40 to 59 years, and four (20\%) aged 60 years and older. The median age was 42.5 years (IQR $29.75-50.25)$. Half of the patients $(50 \%)$ were men. No patients had a history of exposure to the Huanan seafood market and all 20 patients had been exposed to individuals with confirmed SARS-Cov-2 infection. Among 20 patients, 11 (55\%) had residential history in Wuhan, and the other 9 (45\%) had made contact with patients from affected areas before illness onset. Of the 11 patients with different epidemiological histories resided in Wuhan, 4 (36.4\%) were aged 20-39 years, 5 (45.5\%) were aged 40-59 years, and $2(18.1 \%)$ was older than 60 years. The median age of patients was 43 years (IQR 29 - 48, table 1).

Table 1: 20 COVID-19 patients' demographical and clinical characteristics in Sichuan province 


\begin{tabular}{|c|c|c|c|c|c|c|}
\hline \multirow[b]{2}{*}{ Age (years) (Median, IQR) } & \multicolumn{2}{|c|}{$\begin{array}{l}\text { All patients }(n= \\
20)\end{array}$} & \multicolumn{2}{|c|}{$\begin{array}{l}\text { Having residential } \\
\text { history in Wuhan (n } \\
=11 \text { ) }\end{array}$} & \multicolumn{2}{|c|}{$\begin{array}{c}\text { Have contacted with } \\
\text { patients from affected } \\
\text { areas }(\mathrm{n}=9)\end{array}$} \\
\hline & 42.5 & $\begin{array}{l}(29.75- \\
50.25)\end{array}$ & 43 & $(29-48)$ & 37 & $(31-57)$ \\
\hline \multicolumn{7}{|l|}{ Age groups (n, \%) } \\
\hline $20-39$ & 9 & 45 & 4 & 36.4 & 5 & 55.6 \\
\hline $40-59$ & 7 & 35 & 5 & 45.5 & 2 & 22.2 \\
\hline$\geq 60$ & 4 & 20 & 2 & 18.1 & 2 & 22.2 \\
\hline \multicolumn{7}{|l|}{ Profession (n, \%) } \\
\hline Worker & 5 & 25 & 2 & 18.2 & 3 & 33.3 \\
\hline Clerk & 1 & 5 & 1 & 9.1 & 0 & 0 \\
\hline Office clerk & 5 & 25 & 3 & 27.3 & 2 & 11.2 \\
\hline Freelance & 5 & 25 & 4 & 36.4 & 1 & 11.1 \\
\hline Other & 4 & 20 & 1 & 9.1 & 3 & 33.3 \\
\hline \multicolumn{7}{|l|}{$\operatorname{Sex}(n, \%)$} \\
\hline Male & 10 & 50 & 6 & 54.5 & 4 & 44.4 \\
\hline Female & 10 & 50 & 5 & 45.5 & 5 & 55.6 \\
\hline Underlying diseases & 4 & 20 & 2 & 18.2 & 2 & 22.2 \\
\hline Familial cluster & 4 & 20 & 2 & 9.1 & 3 & 33.3 \\
\hline Fever & 13 & 65 & 8 & 72.7 & 5 & 66.7 \\
\hline \multicolumn{7}{|l|}{ Highest temperature $\left({ }^{\circ} \mathrm{C}\right)(\mathrm{n}, \%)$} \\
\hline$<37.3$ & 10 & 50 & 4 & 36.4 & 6 & 55.6 \\
\hline $37.3-38.0$ & 4 & 20 & 3 & 27.2 & 1 & 11.1 \\
\hline $38.01-39.0$ & 5 & 25 & 4 & 36.4 & 1 & 11.1 \\
\hline$>39.0$ & 1 & 5 & 0 & 0 & 1 & 11.1 \\
\hline Respiratory rate $>20$ breaths per min & 7 & 35 & 4 & 36.4 & 3 & 33.3 \\
\hline Oxygen saturation (\%) (Median, IQR) & 97 & $\begin{array}{l}(96- \\
98.15)\end{array}$ & 96.9 & $(96.0-98.2)$ & 97 & $(94.1-98.5)$ \\
\hline Oxygenation index (Median, IQR) & 423.81 & $\begin{array}{l}(376.9- \\
451.19)\end{array}$ & 429 & $(395-448)$ & 414 & $(326-464)$ \\
\hline Cough (n, \%) & 9 & 45 & 4 & 36.4 & 5 & 55.6 \\
\hline Fatigue $(\mathrm{n}, \%)$ & 6 & 30 & 4 & 36.4 & 2 & 22.2 \\
\hline Sore throat $(n, \%)$ & 10 & 50 & 7 & 64.6 & 3 & 33.3 \\
\hline Chest tightness (n, \%) & 2 & 10 & 0 & 0 & 2 & 22.2 \\
\hline Headache (n, \%) & 3 & 15 & 3 & 27.3 & 0 & 0 \\
\hline Diarrhoea (n, \%) & 3 & 15 & 0 & 0 & 3 & 33.3 \\
\hline Abdominal pain $(\mathrm{n}, \%)$ & 2 & 10 & 0 & 0 & 2 & 22.2 \\
\hline \multicolumn{7}{|l|}{$\begin{array}{l}\text { Number of lesion sites in chest CT (n, } \\
\%)\end{array}$} \\
\hline Single & 3 & 15 & 0 & 0 & 3 & 33.3 \\
\hline More than one & 17 & 85 & 11 & 100 & 6 & 66.7 \\
\hline Incubation time (days) (Median, IQR) & 6.5 & $\begin{array}{l}(3.25- \\
9.0)\end{array}$ & 6 & $(3-8)$ & 8 & $(5.5-10.5)$ \\
\hline $\begin{array}{l}\text { Time from illness onset to first } \\
\text { hospital admission (days) (Median, } \\
\text { IQR) }\end{array}$ & 3.5 & $\begin{array}{l}(1.25- \\
7)\end{array}$ & 3 & $(1-4)$ & 6 & $(2-7.5)$ \\
\hline $\begin{array}{l}\text { Number of close contacts (Median, } \\
\text { IQR) }\end{array}$ & 3 & $(2-4)$ & 3 & $(2-4)$ & 4 & $(2-4.5)$ \\
\hline $\begin{array}{l}\text { Number of confirmed infections } \\
\text { (Median, IQR) }\end{array}$ & 1 & $(1-2)$ & 1 & $(1-1)$ & 2 & $(1.5-2)$ \\
\hline Hospital stays (days) (Median, IQR) & 14 & $\begin{array}{l}(5.25- \\
19.75)\end{array}$ & 15 & $(9-21)$ & 11 & $(2.5-18.5)$ \\
\hline
\end{tabular}




\begin{tabular}{|c|c|c|c|c|c|c|}
\hline Transferred to the hospital (n, \%) & 16 & 80 & 8 & 72.7 & 8 & 88.9 \\
\hline Direct to the hospital (n, \%) & 4 & 20 & 3 & 27.3 & 1 & 11.1 \\
\hline \multicolumn{7}{|l|}{ prognosis of disease } \\
\hline Recovery (n, \%) & 16 & 80 & 10 & 90 & 6 & 66.7 \\
\hline $\begin{array}{l}\text { Transfer to superior medical } \\
\text { institutions }(n, \%)\end{array}$ & 4 & 20 & 1 & 9.1 & 3 & 33.3 \\
\hline
\end{tabular}

IQR: Interquartile range

\section{Clinical features}

Four patients (20\%) had underlying diseases, of which, 2 (10\%) had lung cancer, $1(5 \%)$ had scleroderma and diabetes, and $1(5 \%)$ had diabetes and hypertension. Four of 20 patients $(20 \%)$ showed familial aggregation. 20 patients have provided exact date of close contact with confirmed or suspected COVID19 cases, the median incubation period from exposure to symptoms onset was 6.5 days (IQR 3.25 - 9). The median time from onset of symptoms to first hospital admission was 3.5 days (IQR 1.25 - 7). The median time on the hospital stays was 14 days (IQR 5.25 - 19.75). The most common symptoms at illness onset were fever $(13,65 \%)$, cough $(9,45 \%)$, fatigue $(6,30 \%)$, sore throat $(10,50 \%)$, chest tightness $(2,10 \%)$, headache $(3,15 \%)$, diarrhoea $(3,15 \%)$, and abdominal pain $(2,10 \%)$. Seven $(35 \%)$ patients developed shortness of breath.

Of the 11 patients with residential history of Wuhan, $2(18.2 \%)$ had underlying diseases: one patient had diabetes $(9.1 \%)$, one patient had Lung cancer $(9.1 \%)$. the median incubation period from exposure to symptoms was 6 days (IQR 3 - 8). The median time from onset of symptoms to first hospital admission was 3 days (IQR 1 - 4). The median time on the length of time was 15 days (IQR 9 - 21). The most common symptoms at illness onset were fever $(8,72.7 \%)$, cough $(4,36.4 \%)$, fatigue $(4,36.4 \%)$, sore throat $(7,63.6 \%)$, headache $(3,15 \%)$. Four $(36.4 \%)$ patients developed shortness of breath.

On admission, the blood counts of the $2(10 \%)$ patients showed leucopenia (white blood cell count $<4 \times 10^{9} / \mathrm{L}$ ) and $8(40 \%)$ showed lymphopenia (lymphocyte count $<0.8 \times 10^{9} / \mathrm{L}$; table 2 ). The D-dimer levels were within normal range median $0.345 \mathrm{mg} / \mathrm{L}$ (IQR $0.185-0.55 \mathrm{mg} / \mathrm{L})$. Levels of aspartate aminotransferase increased in $2(10 \%)$ patients. Levels of fasting plasma glucose increased in $10(50 \%)$. Fourteen (82.4\%) patients had normal serum levels of procalcitonin $(<0.1 \mathrm{ng} / \mathrm{mL})$. Abnormalities on chest computed tomograms or radiographs were detected among all of the patients. Seventeen (85\%) patients showed more than one lesion sites in chest radiographs (table 1). Typical chest computed tomography findings of infected patients on admission were bilateral or multiple lobular or subsegmental.

Of 20 patients, 4 patients were transferred to superior medical institutions, one of them was sent into the intensive care unit (ICU) for acute respiratory distress syndrome and received mechanical ventilation, but she was dead at last. Two of them were transferred to an isolation point in medical institutions as their rtPCR results remained positive (table 1).

Fourteen (70\%) patients had been discharged and no one died, $2(10 \%)$ patients were quarantined in a medical facility up to now. Discharge standard was based on abatement of fever for at least three days, 
The pharynx swab nucleic acid test were negative twice every 24 hours, with improved evidence on chest radiography and viral clearance in samples from the lower respiratory tract.

Table 2: Laboratory and chest radiography findings in 20 COVID-19 patients in Sichuan province 
$\mathrm{n}$, The first test $\quad \mathrm{n}$, The second test $\mathrm{n}$, The third test

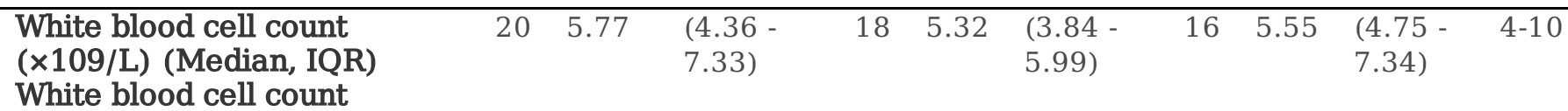

$(\times 109 / \mathrm{L})(\mathrm{n}, \%)$

$\begin{array}{lllllll}<4 & 2 & 10 & 5 & 27.8 & 3 & 18.8 \\ 4-10 & 16 & 80 & 13 & 72.2 & 12 & 75 \\ >10 & 2 & 10 & 0 & 0 & 1 & 6.2\end{array}$

$\begin{array}{llllllllllll}\text { Neutrophil count }(\times 109 / L) & 20 & 4.15 & (3.06- & 18 & 3.27 & (2.55- & 16 & 3.13 & (2.84- & 2-7\end{array}$

$\begin{array}{lllll}\text { (Median, IQR) } & 5.59) & 4.06) & 5.15\end{array}$

$\begin{array}{llllllllllll}\text { Lymphocyte count }(\times 109 / L) & 20 & 0.94 & (0.59- & 18 & 0.99 & (0.81- & 16 & 1.29 & (0.95- & 0.8-4\end{array}$

(Median, IQR)

1.41) 1.56) 1.77)

Lymphocyte count ( $\times 109 / \mathrm{L})$

$(\mathrm{n}, \%)$

$\begin{array}{lllllll}<0.8 & 8 & 40 & 4 & 22.2 & 2 & 12.5 \\ \geq 0.8 & 12 & 60 & 14 & 77.8 & 14 & 87.5\end{array}$

Platelet count $(\times 109 / \mathrm{L})$

(Median, IQR)

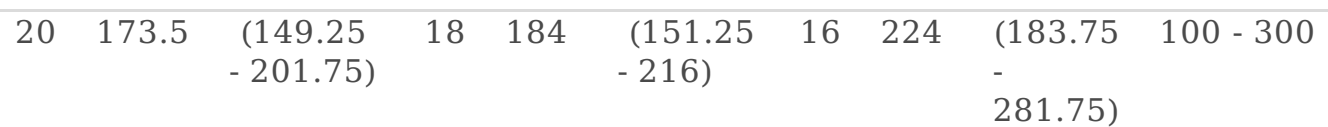

Platelet count

$(\times 109 / \mathrm{L})$

\begin{tabular}{|c|c|c|c|c|c|c|c|c|c|c|}
\hline \multicolumn{2}{|l|}{$<100$} & 1 & \multicolumn{2}{|l|}{5} & 1 & \multicolumn{2}{|l|}{5.6} & 0 & \multicolumn{2}{|l|}{0} \\
\hline \multicolumn{2}{|l|}{$\begin{array}{l}100- \\
300\end{array}$} & 16 & 80 & & 16 & 88.8 & & 14 & 87.5 & \\
\hline \multicolumn{2}{|l|}{$>300$} & 3 & 15 & & 1 & 5.6 & & 2 & 22.5 & \\
\hline $\begin{array}{l}\text { Change in Mean platelet } \\
\text { volume (Median, IQR) }\end{array}$ & 17 & 0.5 & $\begin{array}{l}(0.35- \\
0.8)\end{array}$ & 16 & 1 & $(0.2-1.7)$ & 15 & 0.1 & $\begin{array}{l}(-0.8- \\
1.0)\end{array}$ & \\
\hline $\begin{array}{l}\text { D-dimer (mg/L) (Median, } \\
\text { IQR) }\end{array}$ & 14 & 0.345 & $\begin{array}{l}(0.185- \\
0.55)\end{array}$ & 13 & 0.34 & $\begin{array}{l}(0.17- \\
0.815)\end{array}$ & 11 & 0.33 & $\begin{array}{l}(0.14- \\
0.52)\end{array}$ & $0-0.55$ \\
\hline $\begin{array}{l}\text { Y- glutamate transpeptidase } \\
\text { (U/L) (Median, IQR) }\end{array}$ & 20 & 20.5 & $\begin{array}{l}(15.25- \\
32.5)\end{array}$ & 18 & 20 & $\begin{array}{l}(13- \\
33.5)\end{array}$ & 17 & 22 & $\begin{array}{l}(17.5- \\
33.5)\end{array}$ & $7-45$ \\
\hline $\begin{array}{l}\text { Alanine aminotransferase } \\
(\mathrm{U} / \mathrm{L}) \text { (Median, IQR) }\end{array}$ & 20 & 16.5 & $\begin{array}{l}(13- \\
32.25)\end{array}$ & 18 & 19 & $\begin{array}{l}(12- \\
43.5)\end{array}$ & 17 & 22 & $\begin{array}{l}(17.5- \\
46)\end{array}$ & $7-40$ \\
\hline $\begin{array}{l}\text { Aspartate aminotransferase } \\
\text { (U/L) (Median, IQR) }\end{array}$ & 20 & 25 & $\begin{array}{l}(20.25- \\
32)\end{array}$ & 18 & 30.5 & $\begin{array}{l}(20.74- \\
41.5)\end{array}$ & 17 & 24 & $\begin{array}{l}(19.5- \\
39)\end{array}$ & $13-35$ \\
\hline \multicolumn{11}{|l|}{$\begin{array}{l}\text { Aspartate aminotransferase } \\
(\mathrm{n}, \%)\end{array}$} \\
\hline \multicolumn{2}{|l|}{$<40$} & 17 & 85 & & 13 & 72.2 & & 13 & 76.5 & \\
\hline \multicolumn{2}{|l|}{$\geq 40$} & 3 & 15 & & 5 & 27.8 & & 4 & 23.5 & \\
\hline $\begin{array}{l}\text { Hypersensitive c-reactive } \\
\text { protein (Median, IQR) }\end{array}$ & 20 & 6.49 & $\begin{array}{l}(1.22- \\
2.27)\end{array}$ & 16 & 8.11 & $\begin{array}{l}(0.46- \\
16.84)\end{array}$ & 16 & 3.2 & $\begin{array}{l}(0.43- \\
12.21)\end{array}$ & $0-6$ \\
\hline $\begin{array}{l}\text { Fasting plasma } \\
\text { glucose (mmol/L) (Median, } \\
\text { IQR) }\end{array}$ & 20 & 6.7 & $\begin{array}{l}(5.56- \\
9.63)\end{array}$ & 17 & 6.2 & $\begin{array}{l}(4.98- \\
9.15)\end{array}$ & 16 & 7.4 & $\begin{array}{l}(5.13- \\
9.18)\end{array}$ & $3.89-6.11$ \\
\hline \multicolumn{11}{|l|}{$\begin{array}{l}\text { Fasting plasma } \\
\text { glucose }(\mathrm{mmol} / \mathrm{L})(\mathrm{n}, \%)\end{array}$} \\
\hline \multicolumn{2}{|l|}{$<7.0$} & 10 & 50 & & 11 & 64.71 & & 7 & 43.75 & \\
\hline \multicolumn{2}{|l|}{$\geq 7.0$} & 10 & 50 & & 6 & 35.29 & & 9 & 56.25 & \\
\hline $\begin{array}{l}\text { Blood urea nitrogen(mmol/L) } \\
\text { (Median, IQR) }\end{array}$ & 20 & 3.78 & $\begin{array}{l}(3.33- \\
4.6)\end{array}$ & 18 & 3.07 & $\begin{array}{l}(2.6- \\
3.8)\end{array}$ & 16 & 3.9 & $\begin{array}{l}(2.9- \\
4.25)\end{array}$ & $2.6-7.5$ \\
\hline $\begin{array}{l}\text { Creatine ( } \mu \mathrm{mol} / \mathrm{L}) \text { (Median, } \\
\text { IQR) }\end{array}$ & 20 & 58.15 & $\begin{array}{l}(50.93- \\
77.3)\end{array}$ & 18 & 62.5 & $\begin{array}{l}(50- \\
82.75)\end{array}$ & 16 & 67 & $\begin{array}{l}(54.5- \\
94)\end{array}$ & $44-106$ \\
\hline Creatine kinase $(\mathrm{U} / \mathrm{L})$ & 20 & 62 & $(43.75-$ & 18 & 44.5 & $(34-$ & 16 & 37 & $(27-$ & $40-200$ \\
\hline
\end{tabular}


(Median, IQR)

Creatine phosphokinase

isoenzyme (U/L) (Median,

IQR)

Lactate dehydrogenase

(U/L) (Median, IQR)
112.5)

$20 \quad 12.75 \quad(11-$

14.93)

$20 \quad 234.5 \quad(204-$

335.5)

$\begin{array}{lllllll} & & 82.25) & & 65.5) & \\ 18 & 9.75 & \begin{array}{l}(8.68- \\ 14.1)\end{array} & 16 & 10 & \begin{array}{l}(7.05- \\ 13.4)\end{array} & 0-24 \\ & & & & & \\ 18 & 21.5 & (182.75 & 17 & 195 & \begin{array}{l}(178.5- \\ 244)\end{array} & 120-250 \\ & & - & & & 244)\end{array}$

\section{Lactate dehydrogenase}

(U/L) (n, \%)

262.25)

\begin{tabular}{|c|c|c|c|c|c|c|c|c|c|c|}
\hline$\leq 250$ & & 11 & 55 & & 13 & 72.2 & & 13 & 76.5 & \\
\hline$>250$ & & 9 & 45 & & 5 & 27.8 & & 4 & 23.5 & \\
\hline $\begin{array}{l}\text { Procalcitonin (ng/mL) } \\
\text { (Median, IQR) }\end{array}$ & 17 & 0.1 & $\begin{array}{l}(0.03- \\
0.1)\end{array}$ & 9 & 0.1 & $\begin{array}{l}(0.07- \\
0.2)\end{array}$ & 7 & 0.1 & $\begin{array}{l}(0.09- \\
0.13)\end{array}$ & $0-0.05$ \\
\hline \multicolumn{11}{|l|}{ Procalcitonin (ng/mL) (n, \%) } \\
\hline$<0.1$ & & 14 & 82.4 & & 6 & 66.6 & & 5 & 71.4 & \\
\hline$\geq 0.1$ & & 3 & 17.6 & & 3 & 33.4 & & 2 & 28.6 & \\
\hline
\end{tabular}

IQR: Interquartile range

\section{Discussion}

Up to 1 March 2020, more than 79972 laboratory confirmed cases of infection with COVID-19 were reported in China. The increasing number of infections is slowing down now. However, It is increasing rapidly in other countries now. There are 7651 laboratory confirmed cases of infection with COVID-19 in more than sixty districts. It is possible that an even greater number of infected patients exist without a diagnosis because their symptoms were less severe, also the incubation period was rather long. Only tens of thousands of patients with suspected SARS-Cov-2 infection could eventually receive a diagnosis.

The clinical features of early cases of COVID-19 in Wuhan were not the same as those in other areas of China. According to the data, none of the infected patients in designated medical institutions in Sichuan province had been exposed to the Huanan seafood market, but most of them lived in Wuhan before the onset of the disease, or they had contact history with people who came back from Wuhan recently. The majority of infected patients in our study had same familial cluster, which could be the indirect evidence of transmission by contact, it also suggested human to human transmission. At the same time, it is important to be aware of other transmission ways. The SARS-Cov-2 virus was found in anal swabs and blood as well. It suggest shedding and thereby transmitted through oral-fecal way.

The working group tried to find out whether familial aggregation is related to the path of contact transmission, but there was no definitive answer. It is easy to cause the spread of the disease if the protective measures are not taken among the daily life of the patient. Further detailed investigations should aim to ascertain the exact mode of transmission. It is evidence-based that the general population needs to be carefully screened for COVID-19 from the epidemic area. It can effectively stop SARS-Cov-2 from spreading through the respiratory tract by properly wearing a mask. It plays an important role in the 
early detection and isolation of infectious disease to prevent and control. Quarantine is one of the oldest and most effective tools of controlling communicable disease outbreaks ${ }^{10}$. And that's a very definite fact that we must look at the flow of patients and close contacting people in the prevention and control.

The patients in this study have two basic characteristics. Firstly, all patients had real time polymerase chain reaction for SARS-Cov-2 RNA results. Secondly, chest CT scan revealed specks or frosted glass. The team isolated the suspected patients with only one trait, It was not obtained further confirmation at the end of the observation period when the clinical symptoms and signs of these patients gradually disappeared. Some patients can present with a normal chest finding despite testing positive for COVID$19^{11}$. So there are a lot of COVID-19 patients who will escape confirmed diagnosis, They can also infect people in their daily life if they were not isolated. A combination of repeated swab tests and CT scanning may be helpful for individuals with high clinical suspicion of SARS-Cov-2 infection but negative on RTPCR screening ${ }^{12}$.

The most common clinical symptoms were fever, cough, fatigue, chest distress, etc. Some other symptoms were headache and diarrhea, The laboratory and radiological characteristics, mainly were lymphopenia, increased erythrocyte sedimentation rate, increased C-reactive protein, increased lactate dehydrogenase, decreased oxygenation index, normal white blood cell count and bilateral chest CT involvement. These commonalities have been found in several previous studies ${ }^{13-15}$.

However, some clinical features have not been previously reported. Fasting blood glucose of the infected individuals in Sichuan province were slightly elevated and the glycosylated hemoglobin was normal in the early stages of the disease. It can gradually become normal until the patients is cured. This may have something to do with the inflammatory response affecting the hormonal changes in the body of the patient, which is in a state of emergency. Patients with stress hyperglycemia had more adverse clinical outcomes than patients with normoglycemia ${ }^{16}$. This situation requires us to draw attention in patients with SARS-Cov-2 infection. Lymphocyte count of the infected individuals is mostly reduced before returning to normal. It becomes an opportunistic expression of changes in lymphocyte count that predict disease status. ALT and AST were abnormally elevated in some patients with novel coronavirus infection, but it changes less in people with mild illness, It is basically consistent with the results of Guan, GW studied ${ }^{17}$. Similarly, it is suggestive indicators on the changes of mean platelet volume in disease progress, The result was consistent with previous studies on community-acquired pneumonia ${ }^{18}$.

On the other hand, the working group also found rt-PCR positive but chest radiographs showed that the lesion had been absorbed. It is not clear how to control these patients, according to current the discharge standards. In this study, the pharyngeal swabs of 2 patients remained positive for a long time and they could not discharged from the hospital. It is an important reason that they stayed longer in hospital. For these 2 patients, swabs remain positive for a long time after the clinical symptoms disappeared. It is not clear if they were infectious to the population, that is also a challenge on discharge criteria of cured patients. More evidence has been gathered to confirm this phenomenon gradually in the future.

Page $11 / 14$ 


\section{Limitations Of Study}

This study has several limitations. Firstly, only 20 patients were included. A large number of patients were continually being admitted to hospital as data were being collected, and thus we obtained data on most but not all of the patients with laboratory confirmed infection in Sichuan province during the study period. Secondly, the COVID-19 patients in this study from Sichuan Province only represented a small portion of the total amount of infected cases, the less representativity of clinical features is inevitable. Thirdly, the Patients are transferred to designated medical institutions after being diagnosed by other medical institutions. Therefore, there is a certain bias in the acquisition of clinical data at the initial stage of treatment. Fourthly, the patients were mild illness in designated medical institutions. They will be transferred to the municipal public health center for treatment if the condition of the patient changes suddenly, the working group does not collect clinical data of the patient. All of them could result in biases of clinical observation characteristics. Due to the exploratory nature of the study, which was not driven by formal hypotheses, the sample size calculation was waived.

\section{Conclusion}

Compared with the symptoms of the patients with SARS-Cov-2 infection in Wuhan, those patients from Sichuan province in the study were relatively mild. Most of them recovered after treatment and left safely from the hospital. There is no specific drug to treat COVID-19 and no specific vaccine to prevent it. Therefore, we should adopt a multi-strategy prevention and control means to prevention, combined means to carry out clinical treatment to be developed against SARS-Cov-2 infection as soon as possible.

\section{Declarations}

Acknowledgements: The authors thank Yun-Hui Tan, Jiang-Cuo Luo, Jing Feng, and Juan Li, Yun-Mei Yang, Long Chen, for their hard-working during COVID-19 outbreak and help of reviewing the medical records.

Authors' contribution: ZG and T-YH contributed equally to this article. ZG and L-JC conceptualized the paper. T-YH analyzed the data, with input basic initial data obtained from the study, and ZG. FJ and L-JC wrote the initial draft with all authors providing critical feedback and edits to subsequent revisions. L-YX helped to finalizer the draft. All authors approved the final draft of the manuscript. L-LJ is the guarantor. The corresponding author attests that all listed authors meet authorship criteria and that no others meeting the criteria have been omitted.

Funding: There was no special funding for this study.

Competing interests: All authors have no support from any organization for the submitted work; no financial relationships with any organization that might have an interest in the submitted work in the previous three years; no other relationships or activities that could appear to have influenced the submitted work. 
Ethical approval: This study was approved by the Ethics Committee of Chengdu Fifth People's hospital (AF/72/2020-01.0).

Patient consent: Obtained.

Data sharing: No additional data available.

Transparency: The lead authors and manuscript's guarantor affirm that the manuscript is an honest, accurate, and transparent account of the study being reported; that no important aspects of the study have been omitted; and that any discrepancies from the study as planned have been explained.

Consent of Publication: Written informed consent for publication was obtained from all participants.

\section{References}

1 Park, S; Park, JY; Song, Y; et al. Emerging respiratory infections threatening public health in the AsiaPacific region: A position paper of the Asian Pacific Society of Respirology. [J]. Respirology. 2019, 24 (6): 590 - 597.

2 Chan, JF; Kok, KH; Zhu, Z; et al. Genomic characterization of the 2019 novel human-pathogenic coronavirus isolated from a patient with atypical pneumonia after visiting Wuhan. [J]. Emerg Microbes Infect. 2020, 9 (1): 221 - 236.

3 Zhou, P; Yang, XL; Wang, XG; et al. A pneumonia outbreak associated with a new coronavirus of probable bat origin. [J]. Nature. 2020, published online 3 Feb. doi:10.1038/s41586-020-2012-7.

4 Benvenuto, D; Giovanetti, M; Ciccozzi, A; et al. The 2019-new coronavirus epidemic: Evidence for virus evolution. [J]. J Med Virol. 2020, 92 (4): 455 - 459.

5 Lai, CC; Shih, TP; Ko, WC; et al. Severe acute respiratory syndrome coronavirus 2 (SARS-CoV-2) and corona virus disease-2019 (COVID-19): the epidemic and the challenges. [J]. Int J Antimicrob Agents. 2020, published online 17 Feb. doi:10.1016/j.ijantimicag.2020.105924.

$6 \mathrm{Li}, \mathrm{X}$; Zai, J; Zhao, Q; et al. Evolutionary history, potential intermediate animal host, and cross-species analyses of SARS-CoV-2. [J]. J Med Virol. 2020, published online 27 Feb. doi:10.1002/jmv.25731.

7 Ayittey, FK; Ayittey, MK; Chiwero, NB; et al. Economic Impacts of Wuhan 2019-nCoV on China and the World. [J]. J Med Virol. 2020, published online 12 Feb. doi: 10.1002/jmv.25706.

8 Zu, ZY; Jiang, MD; Xu, PP; et al. Coronavirus Disease 2019 (COVID-19): A Perspective from China. [J]. Radiology. 2020,

published online 21 Feb. doi: 10.1148/radiol.2020200490. 
9 Zhang, W; Du, RH; Li, B; et al. Molecular and serological investigation of 2019-nCoV infected patients: implication of multiple shedding routes. [J]. Emerg Microbes Infect.2020, 9 (1): 386 - 389.

10 Wilder-Smith, A; Freedman, DO; Isolation, quarantine, social distancing and community containment: pivotal role for old-style public health measures in the novel coronavirus (2019-nCoV) outbreak. [J]. J Travel Med.2020, published online 13 Feb. doi:10.1093/jtm/taaa020.

11 Yang, W; Cao, Q; Qin, L; et al. Clinical characteristics and imaging manifestations of the 2019 novel coronavirus disease (COVID-19): A multi-center study in Wenzhou city, Zhejiang, China. [J]. J Infect. 2020, published online 26 Feb. doi:10.1016/j.jinf.2020.02.016.

12 Xie, X; Zhong, Z; Zhao, W; et al. Chest CT for Typical 2019-nCoV Pneumonia: Relationship to Negative RT-PCR Testing. [J]. Radiology. 2020, published online 2 Feb. doi:10.1148/radiol.2020200343.

13 Zhang, JJ; Dong, X; Cao, YY; et al. Clinical characteristics of 140 patients infected with SARS-CoV-2 in Wuhan, China. [J]. Allergy. 2020, published online 13 Feb. doi:10.1111/all.14238

$14 \mathrm{Li}, \mathrm{YY}$; Wang, WN; Lei, Y; et al.[Comparison of the clinical characteristics between RNA positive and negative patients clinically diagnosed with 2019 novel coronavirus pneumonia]. [J]. Zhonghua Jie $\mathrm{He} \mathrm{He}$ Hu Xi Za Zhi. 2020, 43 (0): E02302.

$15 \mathrm{Xu}, \mathrm{XW}$; Wu, XX; Jiang, XG; et al. Clinical findings in a group of patients infected with the 2019 novel coronavirus (SARS-Cov-2) outside of Wuhan, China: retrospective case series. [J]. BMJ. 2020, published online 27 Feb. doi:10.1136/bmj.m792.

16 Soysal, DE; Karakus, V; Seren, AR; et al. Evaluation of transient hyperglycemia in non-diabetic patients with febrile neutropenia. [J]. Eur J Intern Med. 2012, 23 (4): 342 - 6

17 Guan, GW; Gao, L; Wang, JW; et al. Exploring the mechanism of liver enzyme abnormalities in patients with novel coronavirus-infected pneumonia]. [J]. Zhonghua Gan Zang Bing Za Zhi. 2020, 28 (2): E002.

18 Gorelik, O; Tzur, l; Barchel, D; et al. A rise in mean platelet volume during hospitalization for community-acquired pneumonia predicts poor prognosis: a retrospective observational cohort study. [J]. BMC Pulm Med. 2017, 17 (1): 137 